\title{
Klasifikasi Antusiasme Mahasiswa terhadap Perkuliahan Daring Menggunakan Metode $\mathrm{CHAID}$
}

\author{
Riefyal Arshyzha Mustain ${ }^{1, a)}$, Afifi Indrasari ${ }^{1, b)}$, Muhammad Tanaka ${ }^{1, c)}$, Muhammad \\ Sukriansyah ${ }^{1, \mathrm{~d})}$, Edy Widodo ${ }^{1, \mathrm{e})}$ \\ ${ }^{1}$ Program Studi Statistika, Fakultas Matematika dan Ilmu Pengetahuan Alam, Universitas Islam Indonesia \\ Email: a)18611030@ students.uii.ac.id, b) 18611063@students.uii.ac.id, ${ }^{\text {c)}} 18611083 @$ students.uii.ac.id, \\ d)18611062@students.uii.ac.id, e) edywidodo@uii.ac.id
}

\begin{abstract}
The Covid-19 pandemic underlies online learning in many campuses and schools in Indonesia, including Universitas Islam Indonesia in Yogyakarta. The study aimed to discover whether media used in online learning can support learning needs, both for educators and students, or decrease student enthusiasm in learning. The study employed the CHAID method, a part of classification methods. Data were collected using a Google Form questionnaire, followed by descriptive data analysis and CHAID analysis. There was one dependent variable, i.e., student enthusiasm level, and eight independent variables, i.e., media social type, student presence, teaching preparation of lecturers, learning method, learning duration, and assignment intensity. In the FMIPA UII case, six recommendation segments were obtained from 13 segments to minimize the moderate enthusiasm with an accuracy level of $61.25 \%$.
\end{abstract}

Keywords: classification method, CHAID analysis, online lecture, student enthusiasm

\begin{abstract}
Abstrak
Pandemi Covid-19 adalah alasan diadakannya perkuliahan daring dari berbagai kampus maupun sekolah di Indonesia, begitu pun dengan kampus Universitas Islam Indonesia yang terletak di Yogyakarta. Tujuan dilakukannya penelitian ini adalah mengetahui apakah media-media yang digunakan dalam perkuliahan daring dapat menunjang kebutuhan pembelajaran baik bagi pengajar maupun bagi mahasiswa atau justru menyebabkan antusiasme mahasiswa menjadi menurun terhadap perkuliahan dengan metode yang digunakan. Penelitian ini menerapkan metode CHAID yang merupakan salah satu bagian dari metode klasifikasi. Teknik pengumpulan data dilaksanakan menggunakan angket google form lalu dilanjutkan pada tahap analisis data deskriptif dan analisis CHAID. Terdapat 1 variabel dependen yaitu variabel tingkat antusiasme mahasiswa dan 8 variabel independen yang akan digunakan yaitu variabel jenis media sosial, tingkat kehadiran mahasiswa, kegiatan persiapan mengajar dosen, metode pembelajaran, lama waktu kuliah dan intensitas pemberian tugas. Pada kasus FMIPA UII, didapatkan 6 segmen rekomendasi dari 13 segmen untuk meminimumkan antusiasme biasa saja dan tidak baik dengan tingkat akurasi sebesar $61.25 \%$.
\end{abstract}

Kata-kata kunci: metode klasifikasi, analisis CHAID, kuliah daring, antusias mahasiswa 


\section{PENDAHULUAN}

Kemajuan ilmu pengetahuan dan teknologi menjadi aspek utama yang memengaruhi penyesuaian metode pembelajaran serta kurikulum pengajaran. Dengan berkembangnya IPTEK secara tidak langsung akan memengaruhi kurikulum dan metode pembelajaran di setiap perguruan tinggi. Salah satu sifat dari kemajuan ilmu pengetahuan dan teknologi adalah untuk mempermudah manusia dalam mengatasi berbagai masalah dalam kehidupan. Disamping itu, terdapat aspek penting yang menjadi perhatian yaitu kebijakan dalam menghadapi fenomena dan kondisi yang terjadi dalam masyarakat. dimana saat ini Negara Indonesia tengah menghadapi wabah Covid-19 yang mengharuskan diadakannya pembelajaran secara daring (dalam jaringan). Indonesia merupakan negara dengan jumlah pasien terpapar Covid-19 yang cukup tinggi. Penerapan Pemberlakuan Pembatasan Kegiatan Masyarakat (PPKM) masih diterapkan dan akan terus diawasi demi mengantisipasi bertambahnya jumlah orang yang terpapar Covid-19.

Berbagai macam media dapat digunakan dalam menunjang pembelajaran yang dilakukan secara daring seiring dengan berkembangnya teknologi. Namun, yang menjadi hal pertanyaan besarnya yaitu apakah media-media yang digunakan dalam perkuliahan daring dapat menunjang kebutuhan pembelajaran baik bagi pengajar maupun bagi mahasiswa atau justru menyebabkan antusiasme mahasiswa menjadi menurun terhadap perkuliahan dengan metode yang digunakan. Pemerintah dan perguruan tinggi sebagai pemangku kebijakan seharusnya sadar akan hal ini, dapat melakukan pertimbangan yang matang agar sektor pendidikan di Indonesia dapat terjamin kualitasnya dengan baik.

Beberapa penelitian yang sudah dilaksanakan terkait analisis antusiasme mahasiswa selama perkuliahan daring oleh (Syah \& Angellia, 2020), (Herdiana, et al., 2021), (Purnawinadi, 2021). Adapun penelitian yang menerapkan metode analisis Chaid dalam penelitiannya adalah diantaranya (Kunto \& Hasana, 2006), disamping itu terdapat juga temuan dari (Nuriyah, 2013), (Diaz Perez \& Cejas, 2016), (Oktafianto, 2017), (Susanti, et al., 2017), (Nur Syamsi \& Nugraha, 2019), serta penelitian yang dilakuan oleh (Rizki, et al., 2020) dengan judul yang berbeda satu sama lain.

Penelitian tentang aktivitas belajar daring mahasiswa selama pandemi Covid-19 sudah banyak dilaksanakan oleh penelitian terdahulu. Namun demikian, belum terdapat penelitian yang membahas menggunakan metode CHAID. Oleh karena itu, peneliti berminat untuk melaksanakan penelitian tentang Klasifikasi Antusiasme Mahasiswa terhadap Perkuliahan Daring Menggunakan Metode CHAID karena dalam masa perkuliahan daring terdapat berbagai aspek yang menjadikan mahasiswa antusias dalam menjalani perkuliahan. Dengan menggunakan analisis CHAID, maka dapat diidentifikasi aspek mana saja yang menyebabkan mahasiswa antusias terhadap perkuliahan daring sehingga dapat menjadi rekomendasi atau bahkan solusi bagi pemerintah dan perguruan tinggi dalam mengambil kebijakan terkait permasalahan tersebut.

\section{METODOLOGI}

\section{Bahan dan Data}

Untuk melakukan segmentasi antusiasme mahasiswa secara potensial, dapat dengan cara mengimplementasikannya ke dalam metode klasifikasi CHAID. Sistem mempunyai variabel dataset mahasiswa FMIPA UII sebanyak 397 (input). Data dan software yang dipergunakan oleh peneliti ialah data primer, yakni data tingkat antusiasme mahasiswa aktif jenjang diploma dan sarjana FMIPA UII yang akan diolah pada software $R$ Studio dan SIPINA. Data itu selanjutnya dimanfaatkan menjadi variabel untuk melaksanakan analisis CHAID yang terdiri dari variabel independen dan dependen, yang ditampilkan pada TABEL 1. 
TABEL 1. Variabel dan Definisi Operasional Variabel

\begin{tabular}{|c|c|c|c|}
\hline No & & Variabel & Definisi Operasional \\
\hline 1 & $\mathrm{X}_{1}$ & $\begin{array}{l}\text { Jenis media daring yang } \\
\text { digunakan }\end{array}$ & $\begin{array}{l}\text { Media belajar mengajar secara daring yang } \\
\text { dimanfaatkan oleh } \begin{array}{r}\text { dosen } \\
\text { dengan } \\
\text { mempertimbangkan kelebihan dan kekurangan }\end{array} \\
\text { media yang dipergunakan; 1=WhatsApp Grup, } \\
\text { 2=Zoom Meeting, 3=Google Meet, 4=Google } \\
\text { Classroom, 5=lainnya }\end{array}$ \\
\hline 2 & $\mathrm{X}_{2}$ & $\begin{array}{l}\text { Tingkat } \\
\text { mahasiswa }\end{array}$ & $\begin{array}{l}\text { Persentase dari mahasiwa yang ikut saat perkuliahan } \\
\text { daring dengan total adalah } 14 \text { pertemuan; } 1=\text { Tinggi } \\
\text { (di atas dari } 75 \%), 2=\text { Sedang (sebanyak } 50 \%-75 \% \text { ), } \\
3=\text { Rendah (di bawah dari } 50 \% \text { ) }\end{array}$ \\
\hline 3 & $X_{3}$ & $\begin{array}{l}\text { Kegiatan persiapan } \\
\text { mengajar dosen }\end{array}$ & $\begin{array}{llrr}\text { Kesiapan yang dilakukan } & \text { dosen sebelum } \\
\text { melaksanakan perkuliahan; 1=Tidak } & \text { ada, } \\
\text { 2=Menyiapkan materi dalam bentuk } & P P T \text {, } \\
\text { 3=Membuat video pembelajaran, 4=Lainnya } & \end{array}$ \\
\hline 4 & $\mathrm{X}_{4}$ & $\begin{array}{l}\text { Metode } \\
\text { dosen }\end{array}$ & $\begin{array}{l}\text { Cara dosen dalam menciptakan proses kegiatan } \\
\text { belajar mengajar; } 1=\text { Tutorial/menyampaikan materi } \\
\text { secara lisan, } 2=\text { Tugas, } 3=\text { Diskusi dan Tugas, }\end{array}$ \\
\hline 5 & $\mathrm{X}_{5}$ & $\begin{array}{l}\text { Lama waktu perkuliahan } \\
\text { daring }\end{array}$ & $\begin{array}{l}\text { Seberapa lama waktu perkuliahan berlangsung dalam } \\
\text { hitungan menit. }\end{array}$ \\
\hline 6 & $\mathrm{X}_{6}$ & $\begin{array}{l}\text { Intensitas } \\
\text { tugas }\end{array}$ & $\begin{array}{l}\text { Frekuensi dosen dalam memberikan tugas kepada } \\
\text { mahasiswa selama perkuliahan daring; 1=Selalu, } \\
\text { 2=Kadang-kadang, } 3=\text { Tidak pernah }\end{array}$ \\
\hline 7 & $Y$ & $\begin{array}{l}\text { Tingkat } \\
\text { mahasiwa }\end{array}$ & $\begin{array}{l}\text { Persentase kemampuan mahasiwa dalam menyerap } \\
\text { materi selama perkuliahan daring; } 1=\text { Tidak baik } \\
\text { (kurang dari } 40 \%), 2=\text { Biasa saja }(40 \%-60 \%), 3=\text { Baik } \\
(60 \%-80), 4=\text { Sangat baik (lebih dari } 80 \%)\end{array}$ \\
\hline
\end{tabular}

\section{Metode Penelitian}

Terdapat beberapa langkah analisis yang dilakukan untuk melakukan penelitian ini, yaitu:

a. Melakukan penyebaran kuesioner kepada mahasiswa aktif FMIPA UII (data primer).

b. Melakukan pra-analisis data dan menentukan variabel independen dan dependen.

c. Melakukan analisis deskriptif untuk melihat gambaran umum setiap variabel yang akan diteliti.

d. Melakukan proses analisis CHAID.

e. Melakukan pemodelan diagram pohon klasifikasi CHAID untuk menggambarkan pembentukan segmen.

f. Evaluasi klasifikasi untuk mengukur seberapa bagus model bisa mengklasifikasikan data dengan benar. 
Alur segmentasi tingkat antusiasme mahasiswa melalui metode $C H A I D$ bisa dilihat dari deskripsi GAMBAR 1.

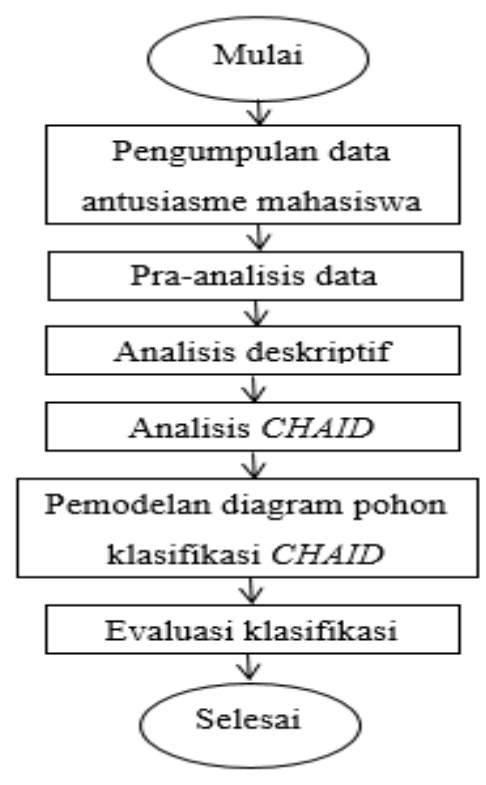

GAMBAR 1. Alur Penelitian

\section{HASIL DAN PEMBAHASAN}

\section{Gambaran Umum Antusiasme Mahasiswa}

Penelitian ini dilaksanakan dengan memanfaatkan survei online kepada semua mahasiswa aktif FMIPA UII dari tanggal 1 Juni 2021 sampai tanggal 25 Juni 2021. Terdapat 397 responden yang melakukan pengisian angket secara tepat waktu. Selanjutnya untuk mengolah data yang sudah terkumpul dapat dilakukan menggunakan statistik.

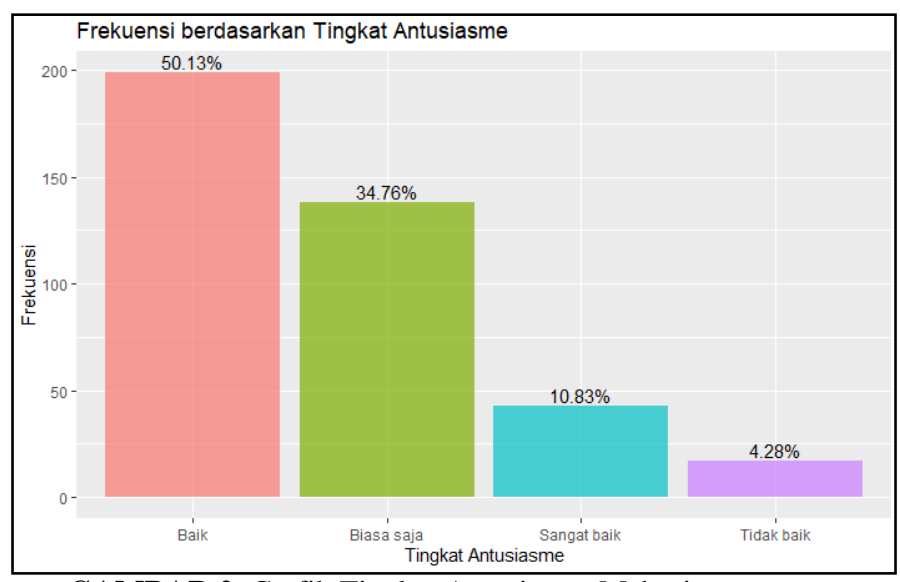

GAMBAR 2. Grafik Tingkat Antusiasme Mahasiswa

Berdasarkan GAMBAR 2, sebanyak 199 mahasiswa (50.13\%) yang menjalani perkuliahan secara daring dapat menerima perkuliahan dengan baik, bahkan sebanyak 43 orang mahasiswa $(10.83 \%)$ menerima perkuliahan daring tersebut secara sangat baik, 17 orang mahasiswa $(4.28 \%)$ yang mengatakan bahwa perkuliahan secara daring tidak baik, dan 138 mahasiswa (34.76\%) mengatakan biasa saja. 


\section{Analisis CHAID}

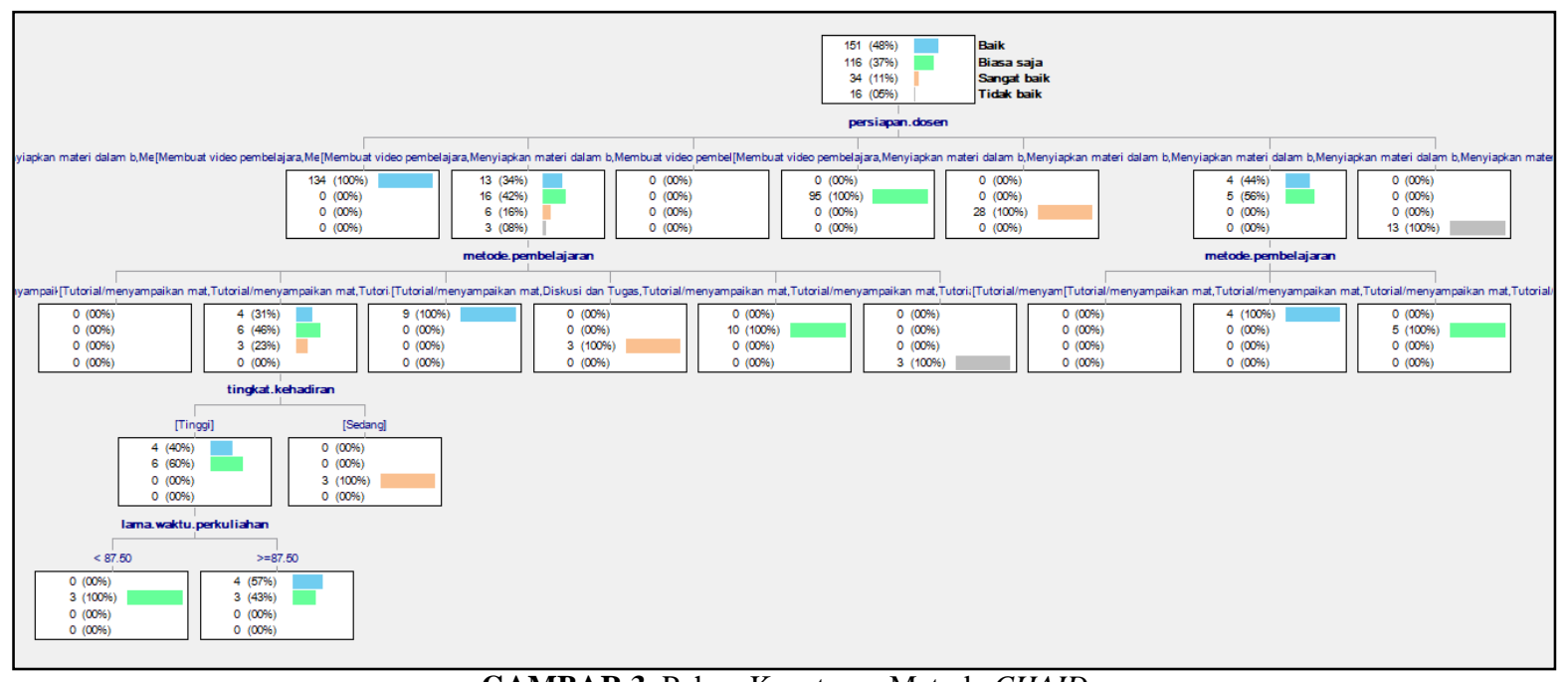

GAMBAR 3. Pohon Keputusan Metode CHAID

Berlandaskan pohon analisis CHAID dalam GAMBAR 3 diperlihatkan bahwa di node teratas memiliki total sejumlah 317 mahasiswa, terdiri dari 34 mahasiswa dengan antusiasme sangat baik (11\%), 151 mahasiwa dengan antusisame baik (48\%), 116 mahasiswa dengan antusisame biasa saja (37\%) dan 16 mahasiswa dengan antusiasme tidak baik (5\%). Variabel independen yang signifikan dan dapat membentuk pohon klasifikasi merupakan variabel metode pembelajaran, persiapan dosen sebelum melakukan pembelajaran, tingkat kehadiran mahasiswa, dan lama waktu perkuliahan.

Berdasarkan pohon keputusan hasil dari klasifikasi dengan metode CHAID di atas, terbentuk $\mathbf{1 3}$ segmen yang berbeda yaitu sebagai berikut:

i. Jika persiapan dosen [menyiapkan materi dalam bentuk PPT, menyiapkan materi dalam bentuk PPT, menyiapkan materi dalam bentuk PPT] maka dari data diperoleh antusias baik sebanyak $134(100 \%)$ dan lainnya 0 . Sehingga tingkat antusiasme pada kelompok ini akan diduga sebagai "Baik". (Segmen 1)

ii. Jika persiapan dosen [lainnya], metode pembelajaran [diskusi dan tugas] dan tingkat kehadiran [tinggi] serta lama waktu perkuliahan $<87.50$ menit maka dari data diperoleh antusias biasa saja sebanyak 3 mahasiswa (100\%) dan lainnya 0. Sehingga tingkat antusiasme pada kelompok ini akan diduga sebagai "Biasa saja". (Segmen 2)

iii. Jika persiapan dosen [lainnya], metode pembelajaran [diskusi dan tugas] dan tingkat kehadiran [tinggi] serta lama waktu perkuliahan $>=87.50$ menit maka dari data diperoleh antusias baik sebanyak 4 mahasiswa (57\%) dan antusias biasa saja sebanyak 3 mahasiswa (43\%) dan lainnya 0. Sehingga tingkat antusiasme pada kelompok ini akan diduga sebagai "Baik". (Segmen 3)

iv. Jika persiapan dosen [lainnya], metode pembelajaran [diskusi dan tugas] dan tingkat kehadiran [sedang] maka dari data diperoleh antusias sangat baik sebanyak 3 mahasiwa (100\%). Sehingga tingkat antusiasme pada kelompok ini akan diduga sebagai "Sangat baik". (Segmen 4)

v. Jika persiapan dosen [lainnya] dan metode pembelajaran [tutorial/menyampaikan materi secara lisan, tutorial/menyampaikan materi secara lisan, tutorial/menyampaikan materi secara lisan] maka dari data diperoleh antusias baik sebanyak 9 mahasiswa (100\%) dan lainnya 0. Sehingga tingkat antusiasme pada kelompok ini akan diduga sebagai "Baik". (Segmen 5)

vi. Jika persiapan dosen [lainnya] dan metode pembelajaran [tutorial/menyampaikan materi secara lisan, tutorial/menyampaikan materi secara lisan, tutorial/menyampaikan materi secara lisan] maka dari data diperoleh antusias sangat baik sebanyak 3 mahasiswa (100\%) dan lainnya 0. Sehingga tingkat antusiasme pada kelompok ini akan diduga sebagai "Sangat baik". (Segmen 6) 
vii. Jika persiapan dosen [lainnya] dan metode pembelajaran [tutorial/menyampaikan materi secara lisan] maka dari data diperoleh antusias biasa saja sebanyak 10 mahasiswa (100\%) dan lainnya 0. Sehingga tingkat antusiasme pada kelompok ini akan diduga sebagai "Biasa saja". (Segmen 7)

viii.Jika persiapan dosen [lainnya], metode pembelajaran [video pembelajaran] maka dari data diperoleh antusias mahasiswa tidak baik sebanyak 3 mahasiswa (100\%). Sehingga tingkat antusiasme pada kelompok ini akan diduga sebagai "Tidak baik". (Segmen 8)

ix. Jika persiapan dosen [membuat video pembelajaran, membuat video pembelajaran, menyiapkan materi dalam bentuk PPT, membuat video pembelajaran, menyiapkan materi dalam bentuk PPT] maka dari data diperoleh antusias biasa saja sebanyak 95 mahasiswa (100\%) dan lainnya 0. Sehingga tingkat antusiasme pada kelompok ini akan diduga sebagai "Biasa saja". (Segmen 9)

x. Jika persiapan dosen [membuat video pembelajaran, menyiapkan materi dalam bentuk PPT, membuat video pembelajaran, membuat video pembelajaran, menyiapkan materi dalam bentuk PPT] maka dari data diperoleh antusias mahasiswa adalah sangat baik sebanyak 28 mahasiswa (100\%) dan lainnya 0. Sehingga tingkat antusiasme pada kelompok ini akan diduga sebagai "Sangat baik". (Segmen 10)

xi. Jika persiapan dosen [membuat video pembelajaran, menyiapkan materi dalam bentuk PPT, menyiapkan materi dalam bentuk PPT, menyiapkan materi dalam bentuk PPT, menyiapkan materi dalam bentuk PPT] maka dari data diperoleh antusias mahasiswa adalah tidak baik sebanyak 13 mahasiswa (100\%) dan lainnya 0. Sehingga tingkat antusiasme pada kelompok ini akan diduga sebagai "Tidak baik". (Segmen 11)

xii. Jika persiapan dosen [tidak ada] dan metode pembelajaran [tutorial/menyampaikan materi secara lisan, tutorial/menyampaikan materi secara lisan, tutorial/menyampaikan materi secara lisan] maka dari data diperoleh antusias mahasiswa adalah baik sebanyak 4 mahasiswa (100\%) dan lainnya 0 . Sehingga tingkat antusiasme pada kelompok ini akan diduga sebagai "Baik". (Segmen 12)

xiii. Jika persiapan dosen [tidak ada] dan metode pembelajaran [tutorial/menyampaikan materi secara lisan, tutorial/menyampaikan materi secara lisan, tutorial/menyampaikan materi secara lisan, tutorial/menyampaikan materi secara lisan] maka dari data diperoleh antusias mahasiswa adalah sangat baik sebanyak 5 mahasiswa $(100 \%)$ dan lainnya 0 . Sehingga tingkat antusiasme pada kelompok ini akan diduga sebagai "Sangat baik". (Segmen 13)

Metode CHAID bisa mengurangi jumlah mahasiswa yang memiliki antusiasme biasa saja dan tidak baik, sehingga peneliti memberi masukan/rekomendasi untuk karakteristik mahasiswa pada Akdemik FMIPA UII yaitu diantaranya:

i. Jika persiapan dosen [lainnya], metode pembelajaran [diskusi dan tugas] dan tingkat kehadiran [tinggi] serta lama waktu perkuliahan < 87.50 menit maka dari data diperoleh antusias biasa saja sebanyak 3 mahasiswa (100\%) dan lainnya 0. Sehingga tingkat antusiasme pada kelompok ini akan diduga sebagai "Biasa saja". (Segmen 2)

ii. Jika persiapan dosen [lainnya] dan metode pembelajaran [tutorial/menyampaikan secara lisan] maka dari data diperoleh antusias biasa saja sebanyak 10 mahasiswa (100\%) dan lainnya 0. Sehingga tingkat antusiasme pada kelompok ini akan diduga sebagai "Biasa saja". (Segmen 7)

iii. Jika persiapan dosen [lainnya], metode pembelajaran [video pembelajaran] maka dari data diperoleh antusias mahasiswa tidak baik sebanyak 3 mahasiswa (100\%). Sehingga tingkat antusiasme pada kelompok ini akan diduga sebagai "Tidak baik". (Segmen 8)

iv. Jika persiapan dosen [membuat video pembelajaran, membuat video pembelajaran, menyiapkan materi dalam bentuk PPT, membuat video pembelajaran, menyiapkan materi dalam bentuk PPT] maka dari data diperoleh antusias biasa saja sebanyak 95 mahasiswa (100\%) dan lainnya 0. Sehingga tingkat antusiasme pada kelompok ini akan diduga sebagai "Biasa saja". (Segmen 9)

v. Jika persiapan dosen [membuat video pembelajaran, menyiapkan materi dalam bentuk PPT, menyiapkan materi dalam bentuk PPT, menyiapkan materi dalam bentuk PPT, menyiapkan materi 
dalam bentuk PPT] maka dari data diperoleh antusias mahasiswa adalah tidak baik sebanyak 13 mahasiswa (100\%) dan lainnya 0. Sehingga tingkat antusiasme pada kelompok ini akan diduga sebagai "Tidak baik". (Segmen 11)

\section{Confusion Matrix}

Model yang diperoleh dari hasil analisis CHAID akan dilakukan perhitungan nilai akurasi, nilai presisi, dan nilai sensitivity agar dapat mengetahui seberapa akurat model dalam mengklasifikasian dengan benar. Adapun berikut merupakan tabel tingkat akurasi melalui penerapkan metode CHAID:

TABEL 2. Nilai Akurasi dari analisis CHAID

\begin{tabular}{ccccc|ccc}
\hline \multirow{2}{*}{ Hasil Seleksi } & \multicolumn{5}{c|}{ Hasil Prediksi } & Hasil & Nilai \\
\cline { 2 - 5 } & Baik & Biasa Saja & Sangat Baik & Tidak Baik & Nilai \\
Akurasi & Presisi & Sensitivity \\
\hline Baik & 47 & 1 & 0 & 0 & & & \\
Biasa Saja & 21 & 1 & 0 & 0 & $61.25 \%$ & $52.75 \%$ & $28.34 \%$ \\
Sangat Baik & 8 & 0 & 1 & 0 & & & \\
Tidak Baik & 1 & 0 & 0 & 0 & & & \\
\hline
\end{tabular}

Keakuratan sebuah model yang telah dibangun diperoleh dari hasil akurasi data testing. Tingkat akurasi analisis CHAID sebesar 61.25\%. Berdasarkan TABEL 2, nilai akurasi diperoleh dari nilai perhitungan manual seperti berikut:

$$
\frac{47+1+1}{417+1+21+1+8+1+1}=\frac{49}{80}=0.6125
$$

\section{KESIMPULAN DAN SARAN}

Berdasarkan pohon klasifikasi yang terbentuk, variabel independen yang signifikan memengaruhi dan dapat membentuk pohon merupakan variabel metode pembelajaran, persiapan dosen sebelum melakukan pembelajaran, tingkat kehadiran mahasiswa, dan lama waktu perkuliahan. Terdapat 13 segmen yang terbentuk dengan rekomendasi karakteristik mahasiswa untuk meminimumkan antusiasme mahasiswa yang biasa saja dan tidak baik adalah segmen 2 , segmen 7 , segmen 8 , segmen 9, segmen 11 .

\section{REFERENSI}

Diaz Perez, F. M \& Cejas, B 2016, 'CHAID Algorithm as an Appropriate Analytical Method For Tourism Market Segmentation', Journal of Destination Marketing \& Management, vol. 5, hh. 275282.

Herdiana, D \& Rudiana, R 2021, 'Kejenuhan Mahasiswa dalam Mengikuti Perkuliahan Daring', Jurnal Ilmiah Pendidikan, hh. 293-307.

Kunto, Y \& Hasana, S 2006, 'Analisis CHAID Sebagai Alat Bantu Statistika Untuk Segmentasi Pasar' Jurnal Manajemen Pemasaran, hh. 88-98.

Nur Syamsi, W. R \& Nugraha, J 2019, 'Penerapan Metode CHAID Menggunakan Smote Dalam Klasifikasi Tingkat Luka Korban Kecelakaan Lalu Lintas Polrestabes Surabaya’, hh. 212-225.

Nuriyah 2013, 'Perbandingan Metode CHAID dan CART dalam Menentukan Klasifikasi Alumni UIN Sunan Kalijaga', Yogyakarta: s.n.

Oktafianto, K 2017, 'Implementasi Metode Chi-Squared Automatic Interaction Detection pada Klasifikasi Indeks Prestasi Kumulatif Mahasiswa FMIPA UNIROW', Technology Science and Engineering Journal, vol. 1, hh. 21-25. 
Purnawinadi, I. G 2021, 'Dampak Pandemi Covid-19 Pada Prestasi Belajar Mahasiswa Keperawatan Tahap Akademik', Jurnal Skolastik Keperawatan, vol. 7, hh. 63-69.

Rizki, M., Umam, M. I. H. \& Hamzah, M. L 2020, 'Aplikasi Data Mining Dengan Metode CHAID Dalam Menentukan Status Kredit’, Jurnal Sains, Teknologi, dan Industri, vol. 18, hh. 29-33.

Susanti, Y. et al 2017, 'Analysisof Chi-Square Automatic Interaction Detection (CHAID) and Classification and Regression Tree (CART) for Classification of Corn Production', IOP Publishing.

Syah, S \& Angellia, F 2020, 'Analisa Pemanfaatan Teknologi Daring Mahasiswa IBI Kosgoro 1957 Selama Pandemi Covid-19 Dengan Regresi Logistik Ordinal', Jurnal Nasional Informatika, hh. 4356. 